\title{
A study to assess and compare facial and dental proportions in attractive smiles
}

\author{
Roseline $\mathrm{M}^{1 *}$, Aishwarya $\mathrm{N}^{2}$, Sangamesh $\mathrm{B}^{3}$, Lekha $\mathrm{K}^{4}$ and Ramesh KN ${ }^{5}$ \\ ${ }^{1}$ Professor, Department of Prosthodontics, SDM College of Dental Sciences and Hospital, Dharwad, Karnataka, India \\ ${ }^{2}$ Assistant Professor, Department of Prosthodontics, SDM College of Dental Sciences and Hospital, Dharwad, Karnataka, India \\ ${ }^{3}$ Associate Professor, Department of Orthodontics, SDM College of Dental Sciences and Hospital, Dharwad, Karnataka, India \\ ${ }^{4}$ Professor and Head, Department of Prosthodontics, SDM College of Dental Sciences and Hospital, Dharwad, Karnataka, India \\ ${ }^{5}$ Professor, Department of Prosthodontics, SDM College of Dental Sciences and Hospital, Dharwad, Karnataka, India
}

\begin{abstract}
The importance of the face as the bearer of identity, character, intelligence, and beauty is universal. There is a universal standard for facial beauty regardless of race, age, sex and other variables. Beautiful faces have ideal facial proportion. All living organisms, including humans, are genetically encoded to develop to this proportion because there are extreme esthetic and physiologic benefits; but vast majority of us are not perfectly proportioned because of environmental factors. Regardless of how attractive the teeth appear in isolation, if spatially they don't relate to rest of the facial structures, then the overall impression will not be esthetic. This paper therefore aims at assessment and co relation of dental and facial proportion influencing the orofacial esthetics.
\end{abstract}

\section{Introduction}

Increasingly patients who seek prosthodontic treatment are primarily concerned with enhancing their oral esthetics. An individuals dentofacial appearance influences social attraction and relationships [1-3]. Regardless of how attractive the teeth appear in isolation, if spatially they don't relate to rest of the facial structures, then the overall impression will not be esthetic [4].

Attractive faces generally follow the facial third proportionality concept. Attractive faces tend to have common proportion and relationship that generally differ from normative values. More attractive faces display optimal balance when they present in proportions [5].

The ideal face is divided vertically into equal thirds by horizontal lines adjacent to hair line, the nasal base and Menton. The interrelationship of the widths of the components of the face are important in the overall proportionality of the face. There are numerous studies about dental intercuspation and occlusion, but less has been written about the relationship between the teeth and oral soft tissues and how this relationship affects the smile esthetics [6].

Proportion is the study of the harmony of structures in space. Lombardi was first to propose the application of golden proportion in dentistry. When the proportion or ratio of the greater part to the whole it is set to be in geometric progression or fibonnacci series. Ideal proportion is directly related to divine proportion and that proportion is 1:1.618. Divine proportion, golden proportion and Phi are synonymous terms. The Phi $=1.618$ [7]. Some parts of the face have been reported to manifest golden proportion. Da Vinci (1896) was fascinated with golden portion. He wrote a book called divine proportion. Golden proportion cannot be addressed without referring to fibonnacci series. Golden proportion is 1.618: 1 and its reciprocal 0.618 in Geometry. The common ratios of the geometric progression are 0.618 and 16.18 . The purpose of this study is to assess the facial and dental proportions in an attractive face.

\section{Material and methods}

A total of 214 students from SDM College of dental sciences and hospitals, Dharwad between the age of 18 - 25yrs with maxillary incisors and canines presenting with anatomic integrity participated in the study. Individuals who had undergone orthodontic treatment, any kind of prosthetic rehabilitation in the maxillary anterior region, fractured or malformed or congenitally missing teeth were excluded from the study.

\section{Inclusion criteria for the study}

1. No obvious asymmetry in the face

2. No dento-facial deformities

3. Pleasant smile

4. No malformation, discoloration or structural deformity of teeth

5. Pleasant dental alignment

\section{Data collection}

The approval to use human subjects was obtained from the governing body of Rajiv Gandhi University of Health Sciences,

Correspondence to: Roseline Meshramkar, Department of Prosthodontics, SDM College of Dental Sciences and Hospital, Dharwad, Karnataka, India, E-mail: roselinemeshramkar@yahoo.co.in

Key words: dental proportion, facial proportion, esthetics, attractive face, dentofacial asthetics, divine proportion, fibonnacci series

Received: June 28, 2017; Accepted: August 11, 2017; Published: August 14, 2017 
Karnataka. Informed consent of individual subject was taken. The subjects were induced to a spontaneous maximum open smile (smile displaying teeth). Frontal photograph of middle and lower third of the face was taken with a Nikon DSLR $200105 \mathrm{~mm}$ Macro lens ratio 1:1F/2.8 digital camera. Lighting and staging were kept constant for all the photographs. Digital management of the photographs was undertaken using Adobe photoshop CS (version 8.0, 2003 Adobe) along with visual examination. All photographs were scanned and saved in personal computer using image measurement programme (Adobe photoshop).

\section{The study was carried out in two stages}

Stage 1: The photographs were assessed for beautiful faces. Out of 214 photographs, beautiful / attractive faces were selected with VAS (Visual Analog Scale). Thirty dental professionals participated in the study. They were asked to assess the attractive faces using VAS (Visual Analog Scale). Those photographs which had mean score of 60 and above with standard deviation of $(\mathrm{SD}=3.45)$ were selected. Out of 214 photographs 33 photographs were selected for attractive faces.

Stage 2: In second part of the study was to assess whether beautiful faces matched golden proportion or proportionality. The facial measurements were performed with following references
Horizontal references: Upper third, Middle third, Lower third,

Vertical references: Tragus to tragus, Outer canthus, Inner canthus, Facial Midline

Dental measurements were performed with the following references: central incisor, lateral incisor, canine, premolar, pmcommisure, inter com, base of the nose to upper lip, Inferior border of the upper lip to incisor edge.

Facial proportion and dental proportion were measured individually and statistical analysis was performed on the data to look for correlation.

\section{Results}

Out of 214 photographs, 33 beautiful / attractive faces were selected with VAS (Visual Analog Scale) and also assessed to see whether beautiful faces matched golden proportion. Table 1 shows the average value of facial measurements (horizontal and vertical references). It was observed that the proportion of lower $3^{\text {rd }}$ of the face was more compared to upper and middle $3^{\text {rd }}$ and proportion of lower $3^{\text {rd }}$ of the face was almost equivalent to upper $3^{\text {rd }}$.

The proportion of inner canthus and outer canthus was equal. Outer canthus and tragus was also equal and the facial fifth was maintained.

Table 1. Average value of facial measurements

\begin{tabular}{|c|c|c|c|c|c|c|c|}
\hline \multirow[b]{2}{*}{ No. } & \multicolumn{3}{|c|}{ Horizontal references } & \multicolumn{4}{|c|}{ Vertical references } \\
\hline & Up third & Mid third & Low third & Tragus to tragus & Out canth & In Canth & Fac Mid \\
\hline 1 & 4.8 & 6.0 & 7.0 & 14.5 & 9.8 & 3.1 & 0.7 \\
\hline 2 & 5.2 & 5.8 & 6.3 & 13.4 & 9.2 & 3.1 & $\square$ \\
\hline 3 & 6.8 & 5.0 & 5.9 & 12.8 & 9.0 & 2.9 & 0.1 \\
\hline 4 & 5.6 & 4.4 & 5.0 & 10.7 & 7.8 & 2.4 & 0.2 \\
\hline 5 & 6.4 & 5.0 & 5.8 & 13.2 & 9.4 & 3 & 0.7 \\
\hline 6 & 5.2 & 5.1 & 5.4 & 12.8 & 10.8 & 2.8 & 0.1 \\
\hline 7 & 6.1 & 4.8 & 6.5 & 12.4 & 10.7 & 3 & $\square$ \\
\hline 8 & 5.1 & 4.6 & 6.4 & 12.8 & 9.5 & 3.2 & 0.4 \\
\hline 9 & 5.9 & 4.8 & 5.7 & 11.9 & 8.5 & 3.1 & 0.1 \\
\hline 10 & 6.2 & 5.0 & 5.9 & 13.5 & 8.3 & 2.7 & $\square$ \\
\hline 11 & 5.6 & 5.5 & 6.4 & 12.7 & 9.3 & 3.3 & 0.6 \\
\hline 12 & 6.6 & 5.6 & 6.4 & 14.2 & 9.4 & 3.2 & 0.2 \\
\hline 13 & 6.5 & 5.6 & 7.1 & 13.8 & 9.4 & 3.0 & 0.3 \\
\hline 14 & 6.0 & 5.7 & 5.9 & 13.8 & 9.8 & 3.3 & 0.7 \\
\hline 15 & 5.7 & 5.4 & 6.1 & 12.8 & 11.2 & 3.3 & 0.5 \\
\hline 16 & 5.1 & 4.7 & 6.1 & 13.1 & 8.9 & 3.1 & 1.2 \\
\hline 17 & 6.0 & 5.0 & 6.0 & 13 & 9.4 & 3.1 & $\square$ \\
\hline 18 & 5.1 & 4.8 & 6.5 & 12.6 & 8.7 & 3.3 & 0.7 \\
\hline 19 & 6.0 & 4.9 & 6.4 & 13.3 & 9.6 & 3.0 & 0.4 \\
\hline 20 & 6.0 & 5.0 & 6.4 & 13.2 & 9.5 & 3.2 & 0.1 \\
\hline 21 & 6.1 & 5.0 & 6.1 & 13.4 & 9.0 & 3.5 & 0.4 \\
\hline 22 & 6.9 & 5.1 & 5.5 & 13.8 & 9.4 & 3.2 & 0.2 \\
\hline 23 & 6.9 & 5.9 & 6.7 & 14.3 & 9.9 & 3.1 & 0.1 \\
\hline 24 & 4.2 & 3.9 & 4.8 & 9.6 & 6.6 & 2.3 & 0.7 \\
\hline 25 & 4.9 & 3.7 & 4.9 & 10.5 & 7.4 & 2.5 & 0.7 \\
\hline 26 & 6.0 & 5.0 & 6.4 & 12.8 & 8.7 & 2.7 & 0.4 \\
\hline 27 & 6.6 & 5.6 & 6.1 & 13.8 & 9.0 & 2.7 & 0.6 \\
\hline 28 & 5.8 & 5.7 & 6.9 & 14.1 & 10.1 & 3.5 & 0.3 \\
\hline 29 & 5.7 & 5.7 & 6.0 & 13.7 & 11.7 & 3.4 & 0.8 \\
\hline 30 & 6.4 & 5.0 & 6.0 & 13.6 & 9.1 & 3.0 & $\square$ \\
\hline 31 & 6.9 & 5.9 & 6.9 & 14.8 & 10.3 & 3.7 & 0.1 \\
\hline 32 & 5.7 & 5.4 & 5.1 & 13.2 & 9.7 & 3.1 & 0.4 \\
\hline 33 & 6.8 & 5.9 & 7.0 & 15 & 10.9 & 3.2 & 0.3 \\
\hline Total & 194.8 & 170.5 & 201.6 & 433.1 & 310 & 101 & \\
\hline Avg & 5.9030303 & 5.1666667 & 6.109091 & 13.12424242 & 9.3939394 & 3.060606 & \\
\hline
\end{tabular}


Table 2 shows the average value of dental proportion. Table 3 shows the co relation of co efficient value of central incisor.

The central incisor, lateral incisor and canine were in line with Fibonacci series.

Buccal corridor was 0.625 of central incisor and it matched with the width of lateral incisor.

\section{Discussion}

The face is the most important individual factor determining the physical appearance, the facial composition is one of the most important issues for the patient. This perspective influences most patients notions of a perfect smile. Aristotle pointed out the value of proportion in esthetics as early as fourth century BC [Lombardi was the first to propose the application of the golden proportion in Dentsply]. Levin in Lis 1978 article explains low golden proportion states to esthetically pleasing dentition and smile [8]. Mack states that the lower $1 / 3^{\text {rd }}$ of the face significantly influences facial appearance many people often have decreased lower facial height. It may be attributed to wear of teeth, loss of vertical dimension or under eruption of the posterior teeth $[9,10]$. In our study it was found that the lower $3^{\text {rd }}$ is more and it is almost equivalent to upper $3^{\text {rd }}$. Middle $3^{\text {rd }}$ was smaller than the upper and lower $3^{\text {rd }}$ of the face. In attractive faces the lower left was more which contradicts the golden proportion, which is in accordance to Preston and Moss et al, [11,12]. The face is divided into 3 zones, upper, middle and lower. To achieve equilibrium and harmonious integration the facial zones should be equal. Role of fifth is used to describe the ideal transverse relationship of the face. The face is divided sagitally into 5 equal parts from helix to helix of the outer ears. Each of the segments should have the same width as the width of an eye [13]. The inner canthus and outer canthus are equal outer canthus and tragus is equal. Facial fifth is maintained. Our findings is in accordance with Server [14]. Some parts of the face have been reported to manifest fibonacci series.

The width of the maxillary central incisor is in golden proportion to the width of lower inscisors and width of lower incisor to canine. When the proportion or ratio of a smaller to greater part is the same as the ratio of the greater part to the whole. It is said to be in geometric progression or a fibonacci series $[15,16]$.

A study was conducted by Abdulla MA in 2002 [17] to determine the relationship between the inner canthal distance and the mesiodistaly

Table 2. Average of dental proportion

\begin{tabular}{|c|c|c|c|c|c|c|c|c|c|c|c|c|c|}
\hline & \multicolumn{2}{|c|}{ central incisor } & \multicolumn{2}{|c|}{ lateral incisor } & \multicolumn{2}{|c|}{ canine } & \multicolumn{2}{|c|}{ premolar } & \multicolumn{2}{|c|}{ pm-commisure } & \multirow[t]{2}{*}{ inter com } & \multirow[t]{2}{*}{ bn-ul } & \multirow[t]{2}{*}{ lbul-ince } \\
\hline & right & left & right & left & right & left & right & left & right & left & & & \\
\hline 1 & 2.3 & 2.3 & 1.6 & 1.6 & 1 & 1 & 0.8 & 0.8 & 2.1 & 2.1 & 16 & 2 & 2.9 \\
\hline 2 & 2 & 2 & 1 & 1.4 & 1 & 1.2 & 0.7 & 1 & 2.5 & 3 & 13.9 & 1.5 & 2.4 \\
\hline 3 & 2.4 & 2.5 & 1.8 & 1.5 & 1.5 & 1.6 & 1.1 & 0.9 & 3 & 3.8 & 19 & 2.5 & 3.5 \\
\hline 4 & 3.0 & 3.2 & 2.1 & 2.1 & 1.9 & 2.1 & 1.8 & 1.3 & 3.7 & 3.3 & 23.8 & 2.8 & 4 \\
\hline 5 & 2.2 & 2.2 & 1.1 & 1.5 & 1.5 & 1.2 & 0.7 & 0.7 & 2.1 & 2.5 & 16 & 2.9 & 2 \\
\hline 6 & 2.2 & 2.1 & 1.5 & 1.5 & 1.5 & 0.9 & 1 & 0.9 & 2.2 & 2.2 & 15.2 & 2.6 & 3 \\
\hline 7 & 2.2 & 2.5 & 2 & 2 & 1.3 & 1.3 & 1 & 1 & 2.3 & 2.3 & 17.5 & 3.2 & 3 \\
\hline 8 & 3 & 3 & 2.2 & 2.2 & 2 & 2 & 1 & 1 & 3 & 3 & 21.3 & 3 & 4 \\
\hline 9 & 2.2 & 2.1 & 1.9 & 1.3 & 1 & 1.2 & 0.8 & 0.4 & 1.8 & 1.9 & 14.5 & 2.9 & 1.5 \\
\hline 10 & 2 & 2 & 1.5 & 1.6 & 1.1 & 1.2 & 0.8 & 0.8 & 2.1 & 2.1 & 15 & 2.9 & 2.1 \\
\hline 11 & 2 & 2.1 & 1.5 & 1.6 & 1.1 & 1.2 & 0.8 & 0.8 & 2.2 & 2.1 & 15 & 2.4 & 2 \\
\hline 12 & 2.3 & 2.1 & 1.6 & 1.6 & 1.4 & 1.4 & 1 & 1 & 2.6 & 2.5 & 16.6 & 1.5 & 1.9 \\
\hline 13 & 2.4 & 2.4 & 1.6 & 1.7 & 1.5 & 1.5 & 0.8 & 0.1 & 2.3 & 2.4 & 15.9 & 3 & 2.4 \\
\hline 14 & 2.3 & 2.4 & 1.6 & 1.6 & 1.4 & 1.4 & 0.9 & 1 & 2.8 & 2.4 & 16.8 & 1.9 & 2.1 \\
\hline 15 & 2.4 & 2.4 & 1.6 & 1.8 & 1 & 1 & 0.9 & 0.8 & 2.5 & 2.5 & 16 & 2 & 2.1 \\
\hline 16 & 3.2 & 3.1 & 2 & 2.1 & 1.6 & 1.6 & 1.5 & 1.3 & 3.5 & 3 & 21.8 & 0.7 & 4 \\
\hline 17 & 2.4 & 2.4 & 1.6 & 1.9 & 1.5 & 1.3 & 0.4 & 1 & 2.1 & 1 & 16 & 1.4 & 2.4 \\
\hline 18 & 2.2 & 2.3 & 1.5 & 1.1 & 1.2 & 1 & 0.7 & 0.9 & 2.5 & 1.8 & 15.3 & 2.5 & 2.6 \\
\hline 19 & 2.4 & 2.2 & 1.7 & 1.5 & 2 & 1.8 & 2.7 & 1 & 2.8 & 1.8 & 16.7 & 1.9 & 3 \\
\hline 20 & 2.1 & 2.5 & 1.6 & 1.5 & 1.5 & 1.1 & 1.1 & 0.9 & 2 & 1.5 & 14.3 & 2.1 & 2.5 \\
\hline 21 & 2.2 & 1.9 & 1.5 & 1.5 & 1.2 & 1.5 & 0.8 & 0.8 & 2 & 2.6 & 15.6 & 2 & 3 \\
\hline 22 & 2.2 & 1.9 & 1.4 & 1.6 & 1.2 & 1.5 & 0.9 & 0.9 & 1.9 & 2.1 & 17.7 & 2 & 3 \\
\hline 23 & 2.1 & 2.2 & 1.4 & 1.5 & 1.5 & 1.6 & 0.6 & 0.9 & 3.5 & 3.9 & 18.5 & 2.5 & 1.8 \\
\hline 24 & 2.1 & 2.4 & 2 & 2 & 2 & 1.6 & 0.9 & 1.3 & 2.4 & 1.8 & 17 & 1.5 & 3.1 \\
\hline 25 & 2.1 & 2.2 & 1.7 & 1.7 & 1.5 & 1.4 & 1.1 & 1.2 & 2.2 & 1.8 & 16.6 & 2.5 & 3.3 \\
\hline 26 & 1.9 & 1.8 & 1.6 & 1.3 & 1.1 & 1.3 & 0.7 & 0.7 & 2.3 & 2.1 & 13.7 & 1.1 & 2.2 \\
\hline 27 & 2.1 & 2.4 & 1.6 & 1.6 & 1.2 & 1.4 & 0.7 & 1 & 1.8 & 2.3 & 15 & 2.3 & 1.7 \\
\hline 28 & 2.5 & 2.4 & 1.6 & 1.5 & 1.4 & 1.6 & 0.9 & 0.8 & 2.5 & 2.1 & 16 & 2 & 2.7 \\
\hline 29 & 2.5 & 2.5 & 1.8 & 1.8 & 1 & 1.4 & 1 & 1 & 3.5 & 3 & 19 & 1.5 & 3.3 \\
\hline 30 & 2.2 & 2.2 & 1.7 & 1.7 & 1.3 & 1.6 & 1 & 1 & 3 & 2.6 & 17.5 & 1.2 & 2.7 \\
\hline 31 & 2.3 & 2.2 & 1.6 & 1.4 & 1.5 & 1.1 & 1 & 0.9 & 2.2 & 2.3 & 15.6 & 1.3 & 3 \\
\hline 32 & 2.6 & 2.6 & 1.9 & 1.8 & 1.5 & 1.8 & 1 & 0.8 & 3 & 3.4 & 19.5 & 2.5 & 2.5 \\
\hline 33 & 2.5 & 2.5 & 1.7 & 1.8 & 1.4 & 1.1 & 1 & 1 & 2.3 & 2.6 & 17 & 1.5 & 2.2 \\
\hline Total & 73.5 & 77 & 54.5 & 54.3 & 45.8 & 45.9 & 32.1 & 29.9 & 82.7 & 79.8 & 555.3 & 69.6 & 87.9 \\
\hline Avg & 2.227273 & 2.3333 & 1.6515 & 1.6455 & 1.3879 & 1.3909 & 0.9727 & 0.9061 & 2.5061 & 2.41818 & 16.82727 & 2.1091 & 2.66364 \\
\hline
\end{tabular}


Table 3. Correlation of coefficient value of central incisor

\begin{tabular}{|c|c|c|c|}
\hline Component & measurement value & component & Value \\
\hline CI & 1 & LI & 0.624 \\
\hline CI & 1 & Canine & 0.48 \\
\hline CI & 1 & Premolar & 0.445 \\
\hline Buccal corridor & 1 & CI & 0.625 \\
\hline Inter commisure & 1 & CI & 0.815 \\
\hline Inner canthus & 1 & CI & 0.101 \\
\hline Outer canthus & 1 & CI & 0.126 \\
\hline Lower 2/3rd & 1 & CI & 0.036 \\
\hline Upper 1/3rd & 1 & CI & 0.056 \\
\hline
\end{tabular}

width of the maxillary Central Incisor in terms of fibonacci series and it was found that geometric progression was a reliable produce of maxillary central incisor width.

Scandreff et al, [18] studied the ratio between maxillary Central incisor width and certain antropometric parameters including inter commisural width. Interalar width and they reported that more than one measurement of face was needed to obtain the best predictor model for maxillary central incisor width.

The correlation coefficient value of buccal corridor width of central incisor id 0.625 and it matches with lateral incisor. In our study, it was observed that central incisor was in line with Fibonacci series with lateral incisor and canine. Central incisor, Lateral incisor and canine follows Fibonacci series. In our opinion the use of standardized photograph that were evaluated by us might be effective and reliable method for assessing dento facial esthetics.

\section{Conclusion}

Within the limitations of the present study the following conclusions were drawn -

1. The proportion of lower $3 \mathrm{rd}$ of the face was more compared to upper and middle $3 \mathrm{rd}$ and proportion of lower $3 \mathrm{rd}$ of the face was almost equivalent to upper $3 \mathrm{rd}$.

2. The proportion of inner canthus and outer canthus are equal outercanthus and tragus is equal facial fifth is maintained.

3. The central inscisor, lateral inscisor and canine are in line with Fibonacci series.

4. Buccal corridor is 0.625 of central inscisor and it matches the width of lateral inscisor.

Assessment of dento facial esthetics is one of the key elements in diagnosis and treatment planning in restorative dentistry. It must be understood that there is no universal ideal smile. The most important esthetic goal in achieving dentofacial esthetics is to achieve a balanced smile. However, further studies are needed to establish and validate the correlation of dental and facial proportion influencing dento facial esthetics.

\section{References}

1. Burstone CJ (1958) The intergumental profile. Am J Orthod 44: 1-25.

2. Peck S, Peck L (1995) Selected aspects of the art and science of facial esthetics. Semin Orthod 1: 105-126. [Crossref]

3. Peck S, Peck L (1995) Selected aspects of the art and science of facial esthetics. Semin Orthod 1: 105-126. [Crossref]

4. Shaw WC, Rees G, Dawe M, Charles CR (1985) The influence of dentofacial appearance on the social attractiveness of young adults. Am J Orthod 87: 21-26. [Crossref]

5. Shaw WC, Rees G, Dawe M, Charles CR (1985) The influence of dentofacial appearance on the social attractiveness of young adults. Am J Orthod 87: 21-26. [Crossref]

6. McLaren EA, Rifkin R (2002) Macroesthetics: facial and dentofacial analysis. J Calif Dent Assoc 30: 839-846. [Crossref]

7. Arnett GW, Bergman RT (1993) Facial keys to orthodontic diagnosis and treatment planning, Part II. Am J Orthod Dentofacial Orthop 103: 295-411

8. Morley J (1999) The role of cosmetic dentistry in restoring a youthful appearance. $J \mathrm{Am}$ Dent Assoc 130: 1166-1172. [Crossref]

9. Jefferson Y (2004) Facial beauty--establishing a universal standard. Int J Orthod Milwaukee 15: 9-22. [Crossref]

10. Levin EI (1978) Dental esthetics and the golden proportion. J Prosthet Dent 40: 244 252. [Crossref]

11. Mack MR (1996) Perspective of facial esthetics in dental treatment planning. J Prosthet Dent 75: 169-176. [Crossref]

12. Mack MR (1991) Vertical dimension: a dynamic concept based on facial form and oropharyngeal function. J Prosthet Dent 66: 478-485. [Crossref]

13. Preston JD (1993) The golden proportion revisited. J Esthet Dent 5: 247-251. [Crossref]

14. Moss JP, Linney AD, Lowey MN (1995) The use of three-dimensional techniques in facial esthetics. Semin Orthod 1: 94-104. [Crossref]

15. Powell N, Humphreys B(1984) Proportions of the esthetic face.

16. Sarver DM (1993) The esthetic impact of orthodontics: planning treatment to meet patients' needs. J Am Dent Assoc 124: 99-102. [Crossref]

17. Huntley HE (1970) The divine proportion a study in mathematical beauty. Dover publications 2: 22-29.

18. Lombardi RE (1973) The principles of visual perception and their clinical application to denture esthetics. J Prosthet Dent 29: 358-382. [Crossref]

19. Abdullah MA (2002) Inner canthal distance and geometric progression as a predictor of maxillary central incisor width. J Prosthet Dent 88: 16-20. [Crossref]

20. Scandrett FR, Kerber PE, Umrigar ZR (1982) A clinical evaluation of techniques to determine the combined width of the maxillary anterior teeth and the maxillary central incisor. J Prosthet Dent 48: 15-22. [Crossref]

Copyright: (C2017 Roseline M. This is an open-access article distributed under the terms of the Creative Commons Attribution License, which permits unrestricted use, distribution, and reproduction in any medium, provided the original author and source are credited. 